\title{
A categoria mediação em Hegel, Marx e Gramsci: para suprimir ruídos conceituais
}

\section{Zacarias Gama}

Professor Associado da Faculdade de Educação e do Programa de Pós-graduação em Políticas Públicas e Formação Humana da Universidade do Estado do Rio de Janeiro. Membro da Cátedra REGGEN/UNESCO

\section{Resumo}

O ensaio tem como alvo a categoria mediação definida por Hegel e aqui tomada como objeto com a intenção de apreender o seu significado filosófico. O que justifica tal esforço é a tentativa de superar uma concepção que se tem dela na atualidade, regra geral como sinônimo de simples intermediação entre duas coisas.

Palavras-chave: mediação, Hegel, filosofia.

\section{Abstract}

The analyses targets the category mediation defined by Hegel and taken here as an object with the intent to understand its philosophical meaning. What justifies such an effort is the attempt to overcome a conception that it has at present generally as a synonym for simple intermediaries between both.

Key words: mediation, Hegel, philosophy

\section{Resumen}

El análisis se dirige a categoría de mediación definida por Hegel y tomada aquí como un objeto con la intención de comprender su significado filosófico. Lo que justifica tal esfuerzo es el intento de superar una concepción que tiene en la actualidad generalmente como sinónimo de intermediarios simples entre ambos.

Palabras clave: mediación, Hegel, filosofía

\section{Introdução}

A mediação como categoria definida por Hegel é aqui tomada como objeto com a intenção de apreender o seu significado filosófico. $\mathrm{O}$ que justifica tal esforço é a tentativa de superar uma concepção que se tem dela na atualidade, regra geral como sinônimo de simples intermediação entre duas coisas.

Esta concepção é recorrente. No dicionário Michaelis online, de língua portuguesa, a definição no campo do Direito quer dizer "interferência de uma ou mais potências, junto de outras dissidentes, com o objetivo de dirimir pacificamente a questão ocorrente, propondo, encaminhando, regularizando ou concluindo quaisquer negociações 
nesse sentido”. O próprio Conselho Nacional das Instituições de Mediação e Arbitragem (CONIMA), existente no Brasil, também obedece a esta mesma compreensão dicionarizada ao incentivar as práticas de mediação para a solução de conflitos. $\mathrm{O}$ CONIMA assim define a mediação:

"Um processo não adversarial e voluntário de resolução de controvérsias por intermédio do qual duas ou mais pessoas, físicas ou jurídicas, buscam obter uma solução consensual que possibilite preservar o relacionamento entre elas. Para isso, recorrem a um terceiro facilitador, o mediador - especialista imparcial, competente, diligente, com credibilidade e comprometido com o sigilo; que estimule, viabilize a comunicação e auxilie na busca da identificação dos reais interesses envolvidos" (CONIMA, 2015).

Até em diversos trabalhos acadêmicos a categoria é entendida do mesmo modo. Tomando como exemplo o texto "Representação política e organizações civis: novas instancias de mediação e os desafios da legitimidade” (2006), verifica-se que os seus autores compreendem a categoria do mesmo modo ao situarem as organizações civis como intermediárias entre a população e os processos eleitorais.

"Não há qualquer garantia a priori de as eventuais dinâmicas de representação política ativas no universo das organizações civis serem representativas em si pelo simples fato de ocorrerem no plano societário. Caso elas se desempenhem efetivamente como novas instâncias de mediação entre a população e os processos eleitorais ou, como acontece de fato no Brasil, entre a população e a gestão pública no desenho e na implementação de políticas, as organizações civis apenas poderiam contribuir para a reforma da democracia se elas próprias forem representativas ou mostrarem capacidade para preservar certa tensão na relação entre representantes e representados" (Lavalle; Houtzager; Castello, 2006, p. 55).

O primeiro problema que se apresenta ao considerarmos as definições recorrentes está em saber acerca de suas validades. Efetivamente, o que é uma mediação? Quando as mediações ocorrem? Elas, de fato, ocorrem no ato de dirimir questões ocorrentes por meio de sucessivas idas e vindas? O acordo entre duas ou mais partes litigantes é ele próprio uma mediação?

$\mathrm{Na}$ tentativa de responder a estas questões realizamos um détour em algumas obras de alguns pensadores que trabalharam com o conceito de mediação, a começar por Hegel, Marx e Gramsci. Outros e mais contemporâneos autores, tais como Lukács, Mészáros e Barata-Moura, também abordaram esta categoria em suas obras, mas, a despeito da importância deles na atualidade, somente serão examinados em um texto a ser elaborado futuramente.

O esforço presente no presente texto parte do princípio de que no transcurso do século XIX aos dias de hoje, a precisão conceitual que imprimiram a esta categoria tem sido enfraquecida e até mesmo destituída de seu sentido original.

$\mathrm{O}$ détour pelas obras de Hegel e Marx podem ter diversas justificativas. São dois importantes filósofos do mundo ocidental, ou dois grandes continentes da geografia filosófica como o querido e saudoso Leandro Konder, com toda a sua generosidade acadêmica, elegância e simpatia gostava de afirmar em nossas aulas no Programa de Pós-graduação em Educação da PUC-Rio. Em seu livro "Hegel: a razão quase 
enlouquecida" (1991) ele ainda não atribuía a Marx a mesma dimensão continental de Kant e Hegel. Fazia isto em nossas alegres reuniões, nas palestras que proferia e, possivelmente, em outros escritos. Mas, como bom marxista não poderia deixar de reconhecer a grandiosidade de Marx ou furtar-se de lhe atribuir a mesma dimensão continental.

Gramsci, ainda que distante de ocupar o mesmo status de Kant, Hegel e Marx não poderia ficar de fora deste exercício que nos propomos. Ele é, na acepção de Bobbio, um intérprete original de Marx, além de ser fecundo, complexo e rico (1982, p. 10). Mas, não bastasse esta originalidade, Bobbio, além disso, acrescenta, e temos de concordar, que "Gramsci pode ser considerado e avaliado por si mesmo, independentemente da maior ou menor fidelidade de seu pensamento à imagem legada (quase sacralizada) de Marx" (Id. Ib. p. 19).

\section{A mediação em Hegel}

Para Hegel, logo no prefácio de a Fenomenologia do Espirito, a mediação é a passagem de uma situação para outra; "um tornar-se Outro; é uma mediação; mesmo que seja apenas passagem a outra proposição” (1807) . O que permite esta passagem é a reflexão sobre si mesmo. Tal passagem é caracterizada pelo apossar-se de dado objeto imediato pela consciência e a mediação "seria sinal de que não se está de posse do objeto mesmo, mas de algo que sofreu alguma influência por parte da consciência" (Gaboardi, 2013, p. 43).

A mediação, então, nas palavras do próprio Hegel

“... não é outra coisa senão a igualdade-consigo-mesmo semovente, ou a reflexão sobre si mesmo, o momento do Eu para-si-essente, a negatividade pura ou reduzida à sua pura abstração, o simples vir-a-ser. O Eu, ou o vir-a-ser em geral - esse mediatizar -, justamente por causa de sua simplicidade, é a imediatez que vem-a-ser, e o imediato”.

A mediação na perspectiva em que Hegel a situa, tem, portanto, o sentido de "reflexão sobre si mesmo". O ser imediato, o homem somente supera a sua animalidade em um processo constante de construção de conhecimentos, de tornar-se sujeito, em contínuo vir-a-ser-de-si-mesmo. Sucessivas mediações permitem que se produza a si mesmo, que se torne semovente. No princípio é um ser "essente simples e imediato"; posteriormente, com a reflexão que é capaz de realizar, é o ser mediatizado, diferente e superior ao que existia. Ocorre então a sua passagem de um status para outro. Ele que só lidava com as coisas tal como existiam naturalmente, modifica-se ao observá-las conscientemente, isto é, ao aplicar-se às operações do entendimento produzindo outro nível de consciência para si.

Não é, porém, um simples “emergir da imediatez da vida substancial”. Há que haver esforço em adquirir conhecimentos de princípios e pontos de vista universais. Hegel diz-nos ser necessário esforço para "chegar ao pensamento da Coisa em geral e também para defendê-la ou refutá-la com razões, captando a plenitude concreta e rica segundo suas determinidades" (Hegel, id.). É preciso chegar com rigor e profundidade ao conhecimento da coisa. Somente depois de esforços, o conhecimento e apreciação terão na conversa o lugar que lhes corresponde. 


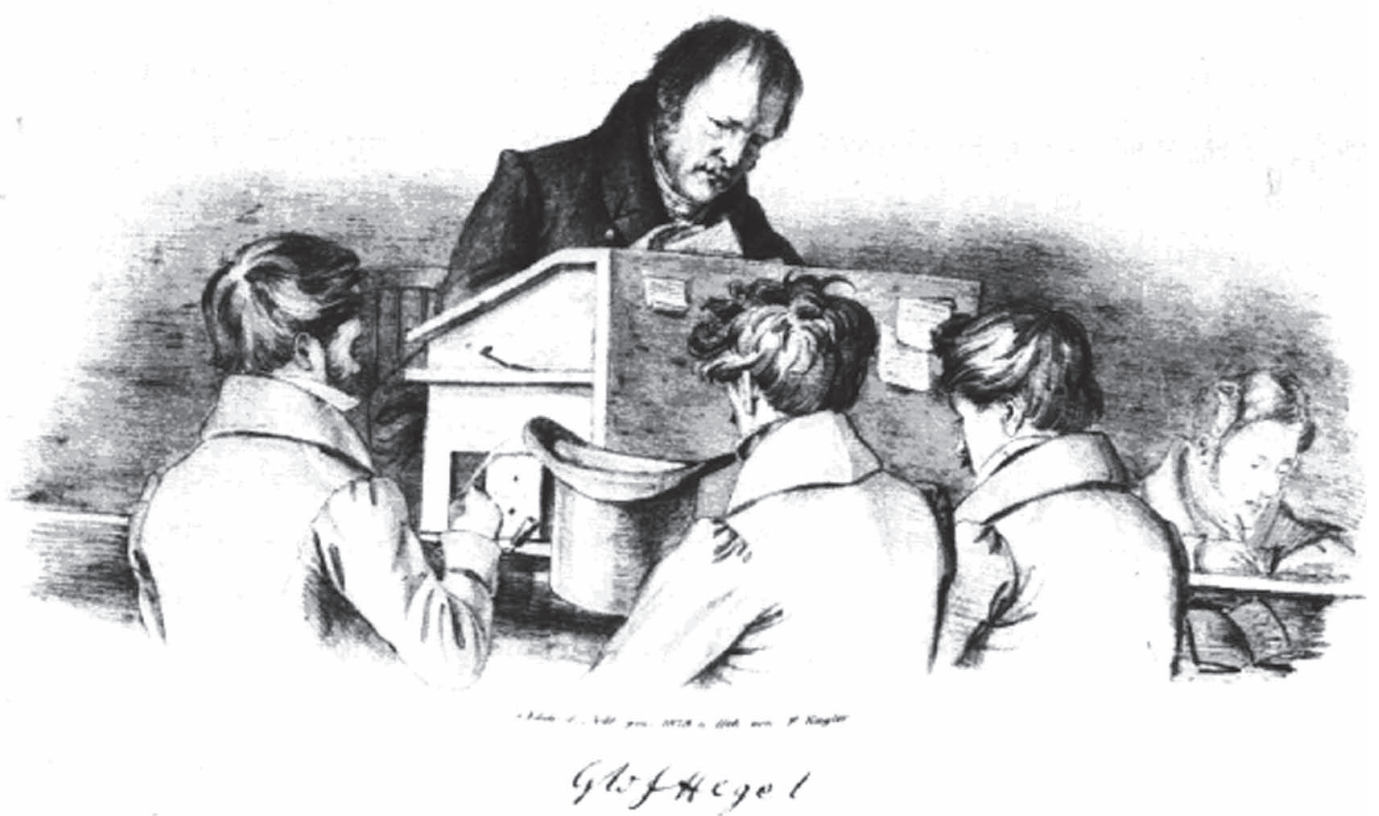

Hegel e estudantes.

Hegel, no entanto, ao ir além das mediações individuais, do ser individual em contínuo vir-a-ser-de-si-mesmo, produtor de seus próprios conhecimentos, fornece-nos os elementos para analisarmos aquela compreensão jurídica que ainda hoje é usual e que destacamos acima; ao mesmo tempo também nos dá pistas para entendermos as mediações que se dão coletivamente, isto é nas relações sociais e políticas. Ele admite que a sociedade civil é o espaço onde ocorre a mediação entre elementos considerados naturais (o conflito, a luta, a concorrência) de uma racionalidade negativa e o aspecto ético-político da racionalidade positiva do Estado. O exemplo prático que nos oferece é o que situa as assembleias de ordem como órgãos de mediação entre o governo e o povo como se pode observar a seguir, em um fragmento de sua obra Princípios da Filosofia do Direito:

"Consideradas como órgãos de mediação, as assembleias de ordem situam-se entre o governo em geral e o povo disperso em círculos e indivíduos diferentes. Delas exige a sua própria finalidade tanto o sentido do Estado, e a dedicação a ele, como o sentido dos interesses dos círculos e dos indivíduos particulares. Simultaneamente significa tal situação uma comum mediação com o poder governamental organizado de modo a que o poder do príncipe não apareça como extremamente isolado nem, por conseguinte, como simples domínio ou arbitrariedade, e assim que não se isolem os interesses particulares das comunas, das corporações e dos indivíduos. Graças a essa mediação, os indivíduos não se apresentam perante o Estado como uma massa informe, uma opinião e uma vontade inorgânica, poderes maciços em face de um Estado orgânico” (Hegel, 1997, p. 278).

Os integrantes das assembleias de ordem posicionados entre os interesses do governo e os do povo são responsáveis pela harmonização das partes interessadas, ambas devidamente subordinadas às convenções do plenário. Os indivíduos do povo são levados a refletir sobre os seus interesses e a apresentá-los com a configuração 
adequada ao enfrentamento com o Estado, e este seguramente também promove as suas próprias reflexões. As discussões podem ocorrer tendo de antemão ponderados os riscos, vantagens e desvantagens até que as partes se deem por satisfeitas. As assembleias de ordem como terceiro facilitador medeiam a reconciliação das partes, com diligência viabilizam a comunicação e ajudam identificar os reais interesses envolvidos. Em seu transcurso o processo de mediação busca harmonizar os interesses do poder governamental organizado com os interesses coletivos das comunidades, das corporações e do próprio indivíduo. É por estas razões que o CONIMA admite que com a mediação é possível se chegar aos acordos das vontades (CONIMA, 2015). As reflexões em presença do terceiro mediador resultam como melhores e superiores àquelas que existiam preliminarmente.

\section{A mediação em MARX}

Marx fez críticas contundentes ao sistema de mediação construído por Hegel, bem como ao seu procedimento filosófico típico do idealismo alemão. É, entretanto, importante observar que ele não nega a mediação como reflexão sobre si mesmo, o simples vir-a-ser. $\mathrm{O}$ criticável para ele é a mediação exclusivamente como atividade cerebral, fechada no ambiente mental e descolada do mundo real. Para Marx, a capacidade que os homens e as mulheres têm de transformar a natureza está nas mediações que podem fazer diante das coisas que os desafiam. Os seres humanos se diferenciam "da melhor abelha porque eles figuram na mente sua construção antes de transformá-la em realidade” (Marx, 1974). Esta possibilidade de criar um determinado projeto primeiro em termos mentais é um processo de mediação, impossível de ser feito pelas demais espécies animais, e é exatamente este mediatizar que permite aos seres humanos criar e recriar a sua própria existência. Nas palavras do próprio Marx:

"O trabalho é, antes de mais, um processo entre homem e Natureza, um processo em que o homem medeia, regula e controla a sua troca material com a Natureza através da sua própria ação [...] Ao atuar, por este movimento, sobre a Natureza fora dele e a transformá-la transforma simultaneamente a sua própria natureza". (Marx, 1974). (Grifo meu).

Para Marx, na perspectiva idealista hegeliana a mediação é apenas um exercício de ideias, realizado pela mente e está circunscrito a ela mesma. É tão somente exercício mental, construção de uma outra realidade que não é verdadeira. Produz abstração como pura ideia da vontade, mistifica a realidade. Confere "ao real uma 'mediação aparente [...] deixando-o intocado em seu conteúdo" (Marx, 2010, p.29).

A concepção de mediação marxiana não poderia ser diferente porque o seu mundo é terreno, material e concreto e se opõe ao mundo idealizado do romantismo hegeliano. No mundo de Marx, os seres humanos ativos têm processos reais de vida, desenvolvem "reflexos [Reflexe] e ecos ideológicos deste processo de vida" (Marx e Engels, 1982). As mediações que fazem deixam, portanto, de ser aparentes; elas são reais e ontocriativas.

Marx também criticou o modo como Hegel situou as assembleias de ordem como órgãos de mediação entre o governo e o povo. Em Hegel, o Estado e governo, como idênticos, são situados em lado oposto ao do povo, este "dissolvido nas esferas 
particulares e nos indivíduos" (Marx, 2010, p. 85). As assembleias, do ponto de vista hegeliano, são o meio, o lugar, onde os interesses opostos devem se encontrar e se unir; as assembleias sintetizariam o Estado e a sociedade civil. Para Marx é um equívoco admitir que as assembleias façam "mediação apenas povo e governo" (Marx, Id. Ib.). Seu argumento é que elas, ao mesmo tempo, impedem que o poder soberano apareça isolado, como "poder dominante e como arbítrio", e que o isolamento do povo se apresente como uma turba. As assembleias não são órgãos de mediação como pretende Hegel, antes são uma proteção do Estado contra a turba inorgânica. Porque simultaneamente são instituições do Estado contra o povo, e deste contra o Estado; nelas as partes envolvidas abdicam da rigidez que demonstravam anteriormente. Para Marx, as assembleias são o termo médio, uma mistura de governo e povo, um mixtum compositum dos dois extremos, do princípio monárquico e da sociedade civil; da singularidade empírica e da universalidade empírica, do sujeito e do predicado" (Id.Ib, p. 101). A mediação que vem à existência nestas assembleias segundo Marx, parece ser tão somente a abdicação das rijezas, elas não apenas permitem que a mediação venha à existência, "mas que elas mesmo sejam a mediação que veio à existência" (Id. Ib. p. 101).

O que Marx efetivamente nos diz é que extremos reais - Estado e Sociedade Civil - não podem ser mediados um pelo outro, "precisamente porque são extremos reais. Mas eles não precisam, também, de qualquer mediação, pois eles são seres opostos" (Id. Ib., 105). Só se alcança nas assembleias a ilusão da possibilidade do acordo que, entretanto, pode ser real e eficaz (Id. Ib. p. 109).

Assim, considerando que cada oposto reflete sobre si mesmo, medeia-se, as assembleias de ordem consideradas por Hegel e Marx e as nossas atuais Instituições de Mediação e Arbitragem melhor seriam denominadas de espaços de acordos entre partes litigantes, nos quais ambas cedem pontos rígidos até onde se tornar possível a satisfação de cada uma. Não há pois mediação das partes, as mediações que fizerem ou fazem sobre si mesmas antes da ocorrência das reuniões é que permitem os acordos, a chegada ao bom termo.

\section{A mediação em GRAMSCI}

Gramsci também utiliza a categoria mediação em diversos momentos de sua extensa obra, sempre a tomando como "processo unitário típico do real" (1999, vol. 1, p. 166). Para ele, o primeiro modelo de mediação dialética é aquele que se dá entre o ser humano e a natureza, no qual se põe "em relação com a natureza através da tecnologia, a conhece e a domina”. Modifica-a e é modificado por ela.

A atividade prática do cientista, segundo este pensador italiano, também é um bom exemplo de mediação. Em um fragmento de texto, ele se expressa assim:

"O cientista experimentador é um operário, não um puro pensador; e seu pensar é continuamente verificado pela prática e vice-versa, até que se forme a unidade perfeita de teoria e prática" (Gramsci, 1999, p. 166).

É interessante observar que Gramsci considera a mediação como "uma cadeia de muitos anéis" (Id.Ib. p. 271). E isto não é por acaso. A mediação nos dizeres de Hegel é um processo constante de tornar-se sujeito, o continuo vir-a-ser-de-si-mesmo. Sua 


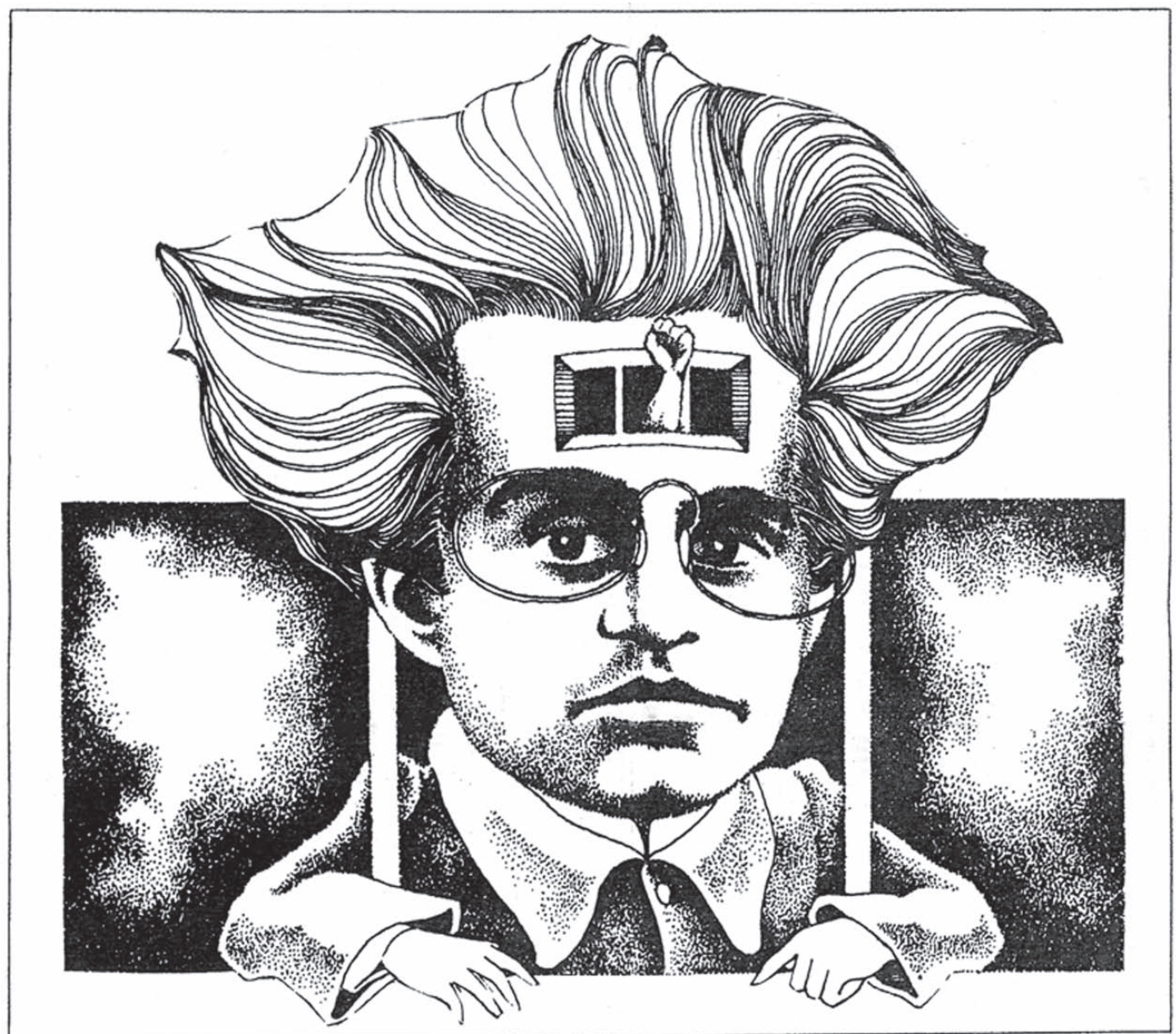

Gramsci. Desenho de Wiaz/ Pierre Wiazemsky.

aproximação ao sistema hegeliano de mediações permite-lhe este entendimento. Mas, tal como Marx, critica-a mediação quando inteiramente intelectualista, com ocorrência exclusiva na mente humana onde se constrói uma outra realidade que não é verdadeira, que se produz mistificada. Ele, ao examinar o artigo de Ugo Spirito, publicado na Italia Letteraria de 13 de novembro de 1932, observa que o seu autor, embora sem saber, desenvolve uma posição que é uma mediação ou superação arbitrária. Em suas palavras:

"Mas Spirito não sabe ir além da superfície dos fatos e das ideias; e, embora afirme, como o anti-Proudhon, ser necessário que os termos dialéticos se explicitem em toda a sua força como "extremismos" contrapostos, não consegue ver que sua própria posição é uma mediação ou superação arbitrária, na medida em que se baseia na supressão violenta da antítese e na proposição como antítese, exatamente, de uma tentativa de mediação inteiramente intelectualista, viva apenas no cérebro de poucos intelectuais de estatura menor" (Id. Ib., p. 450).

Este basear-se de Spirito na supressão da antítese e na proposição como antítese é uma mediação intelectualista, à qual Marx se referiu antes, alertando que não está fundada na realidade concreta porque se inscreve nos domínios da razão e do espírito. A mediação que somente existe no cérebro é incapaz de determinar a ação por ser 
um momento do pensamento. Marx não poupou críticas às produções idealistas e Gramsci à análise filosófica de Croce, da qual ressaltou o seu "caráter pouco concreto" (Gramsci, 1999, vol.1, p. 314). Todavia, diferentemente de Croce, Gramsci não trabalha com princípios gerais, mas com a história concreta, cuja "historicidade e dialética dá lugar a lutas de sistemas, a lutas entre maneiras de ver a realidade” (Id. Ib. p. 368).

A categoria mediação tem presença marcante nos escritos de Gramsci, contudo é preciso ressaltar e deixar bem claro que ele a reserva com exclusividade para as pessoas, a reflexão sobre-si-mesmo os seres humanos podem fazer. O termo "catarse", muito embora possa ser traduzido como um processo de mediação, não é usado para pessoas. Ele serve para marcar as passagens, isto é, o ser outro dos sentimentos populares, do processo dialético, da história, de uma determinada vida prática, do momento econômico etc. Neste sentido o termo catarse tem força própria e se apresenta como variante de seu entendimento de mediação. Em suas próprias palavras:

"Pode-se empregar a expressão "catarse "para indicar a passagem do momento meramente econômico (ou egoístico-passional) ao momento ético-político, isto e, a elaboração superior da estrutura em superestrutura na consciência dos homens. Isto significa, também, a passagem do "objetivo ao subjetivo" e da "necessidade a liberdade". A estrutura, de forca exterior que esmaga o homem, assimilando-o e o tornando passivo, transforma-se em meio de liberdade, em instrumento para criar uma nova forma ético-politica, em origem de novas iniciativas. A fixação do momento "catártico" torna-se assim, parece-me, o ponto de partida de toda a filosofia da práxis; o processo catártico coincide com a cadeia de sínteses que resultam do desenvolvimento dialético. (Recordar os dois pontos entre os quais oscila este processo: que nenhuma sociedade se coloca tarefas para cuja solução já não existam ou estejam em vias de aparecimento, as condições necessárias e suficientes; - e que nenhuma sociedade deixa de existir antes de haver expressado todo o seu conteúdo potencial.)",

O que Gramsci clarifica nesta citação é que a estrutura, isto é a base real da sociedade, ao desenvolver-se dialeticamente se contradiz à superestrutura e promove profundas mudanças na superestrutura erigida sobre ela; neste momento, ao fazer isto, realiza a sua catarse. O momento catártico, como diz, torna-se o ponto de partida de um novo tempo histórico, e de maneira alguma se trata de uma simples elevação da consciência dos homens, verifica-se concretamente a superação do "ponto de passagem 'lógico’ de toda concepção do mundo, da moral que lhe é conforme”. (Id. Ib. p. 336). A filosofia da práxis neste contexto é real e tende a subverter o mundo, a práxis, não mais vive cerebrinamente; deixa de ser arbitrária e se torna necessária, racional, real.

\section{Conclusões}

Face às questões de estudo propostas inicialmente, é possível agora obter as seguintes respostas.

A mediação é a reflexão que um ser humano é capaz de fazer na relação que estabelece com as coisas do mundo real. É um processo de contínuo via-a-ser-de-si-mesmo. Uma cadeia de muitos anéis que permite ao ser humano produzir-se a si mesmo. Não por outra razão que Marx disse que "não é a consciência que determina a vida, é a vida que determina a consciência”. De fato, todas as ideias, representações 
e a consciência dos seres humanos estão diretamente relacionadas com a atividade material de produção de suas existências e com as relações sociais que estabelecem com os seus semelhantes; são eles, os seres humanos concretos, que produzem as suas representações, ideias etc. "A consciência [das Berwusstsein], nunca pode ser outra coisa senão o ser consciente [das berwusste Sein], e o ser dos homens é o seu processo real de vida" (Marx, 1982].

As mediações humanas ocorrem em meio aos desafios de produzir e reproduzir as condições materiais de suas existências e às suas relações de intercâmbio com os outros iguais. Diferentemente do melhor pássaro tecelão da Namíbia ou das melhores abelhas e aranhas somente os seres humanos são os únicos que podem projetar mentalmente as suas construções antes de edificá-las concretamente. As mediações apenas restritas aos domínios do cérebro não determinam as ações de transformação do real, são tão somente exercícios intelectualistas, são momentos do pensamento.

Tem, portanto, sido um equívoco comum considerar o ato de dirimir questões ocorrentes por meio de sucessivas idas e vindas como um mediatizar. Quando examinamos a conceituação do CONIMA para o ato de mediar e a situação das assembleias de ordem entre o governo e o povo parecia inicialmente que de fato o Conselho Nacional das Instituições de Mediação e Arbitragem e tais assembleias promoviam o ser outro dos litigantes e do governo e povo. O exame mais acurado, no entanto, demonstra que o Conselho e as assembleias efetivamente negociam vantagens possíveis para ambas as partes em determinado stablishment. São espaços de entendimento, de negociação. As dirimições não transformam as partes litigantes em outras, nem tampouco se pode afirmar ter existido alguma catarse.

À propósito, é igualmente equivocada a utilização da categoria mediação pedagógica nos termos em que é entendida, por exemplo, por Masetto, Behrens \& Novas (2000, p. 9): "Por mediação pedagógica, entendemos a atitude e o comportamento do professor que se coloca como um facilitador, incentivando ou motivando da aprendizagem".

Nos termos dos autores, a mediação pedagógica corresponde tão somente à ação docente de facilitar, incentivar e motivar a aprendizagem. Uma ação externa sem garantias de que possa produzir alguma reflexão-sobre-si-mesmo. Para os autores que permitem o enquadramento teórico da categoria mediação em nossa exposição, de um ponto de vista epistemológico ou ontológico e apenas considerando o ser em sua individualidade, a mediação é exclusivamente produzida por ele, é um momento do Eu para-si-essente. Todo o processo ocorre mentalmente. A grande divergência entre os entendimentos de Hegel, Marx e Gramsci, é que, enquanto para o primeiro a mediação é um processo mental, abstrato e construtor de uma realidade que não é verdadeira, para os dois últimos ela decorre das reflexões sobre a concretude do processo de vida, das relações que os seres humanos estabelecem com a natureza e com os seus iguais, em suas relações sociais.

Por fim, vale ressaltar que a limitação deste texto às compreensões de Hegel, Marx e Gramsci acerca da categoria mediação não significou qualquer desprezo pelos estudos atuais de György Lukács, István Mészáros e José Barata-Moura, nos quais também empregam largamente esta mesma categoria. Meu objetivo foi o de revisitar o modo como Hegel, Marx e Gramsci a conceituam e aplicam para comparar com os seus empregos atuais no meio jurídico e em diversos textos acadêmicos. Em um texto futuro, tomaremos como objeto as conceituações de Lukács, Mészáros e Barata-Moura. 


\section{Referências Bibliográficas e sitográficas}

CONIMA. Regulamento Modelo Mediação. Disponível no site: http://www. conima.org.br/regula_modmed. Acesso em Junho de 2015.

LAVALLE, Adrián Gurza; HOUTZAGER, Peter P; CASTELLO, Graziela. Representação política e organizações civis: novas instancias de mediação e os desafios da legitimidade. RBCS Vol. $21 \mathrm{n}^{\mathrm{o}}$. 60 fevereiro/2006.

BOBBIO, N. O conceito de sociedade civil. Rio de Janeiro: Edições Graal, 1982.

HEGEL, G. W. F. Prefácio à Fenomenologia do Espirito. Biblioteca Marxista na Internet. https://www.marxists.org/portugues/index.htm. Acesso em Junho de 2015

GABOARDI, E. A. A fenomenologia do espirito de Hegel: uma introdução à seção "consciência". Porto Velho-RO: EDUFRO, 2013.

HEGEL, G. W. F. Princípios da filosofia do direito. São Paulo: Martins Fontes, 1997.

MARX, K. O Capital, vol. 1. Centelha - Promoção do Livro, SARL, Coimbra, 1974. Disponível no site: https://www.marxists.org/portugues/marx/1867/ocapital-v1/vollcap07.htm\#topp. Acesso em Junho de 2015.

MARX, K. Crítica da filosofia do direito de Hegel. São Paulo: Boitempo, 2010.

MARX, K; ENGELS, F. A Ideologia Alemã. Editorial “Avante!" - Edições Progresso Lisboa - Moscou, 1982. Disponível no site: https://www.marxists.org/portugues/ marx/1845/ideologia-alema-oe/index.htm. Acesso em junho de 2015.

MARX, K. Crítica da filosofia do direito de Hegel. São Paulo: Boitempo, 2010.

GRAMSCI, A. Cadernos do cárcere, volume 1. Rio de Janeiro: Civilização Brasileira, 1999.

GRAMSCI, A. Cadernos do cárcere, volume 1. Rio de Janeiro: Civilização Brasileira, 1999.

MARX, K; ENGELS, F. A Ideologia Alemã. Editorial “Avante!” - Edições Progresso Lisboa - Moscou, 1982. Disponível no site: https://www.marxists.org/portugues/marx/1845/ideologia-alema-oe/index.htm. Sem indicações de página. Acesso em junho de 2015.

MORAN, José Manuel; MASETTO, Marcos T.; BEHRENS, Marilda Aparecida. Novas tecnologias e mediação pedagógica. Campinas: Papirus, 2000. Disponível no site: www.adidatica.com.br/arquivos/MORAN.doc. Acesso em junho de 2015. 